\title{
Elevated Tumor Markers In Coccidioidomycosis of the Female Genital Tract
}

\author{
Ying $W u, M D^{1}$ \\ Stacy Arnold ${ }^{2}$ \\ Tim Kuberski, $M D^{3}$ \\ ${ }^{1}$ Department of Internal Medicine and the ${ }^{3}$ Section of Infectious Disease \\ Maricopa Medical Center \\ Phoenix, Arizona \\ ${ }^{2}$ University of Arizona College of Medicine Phoenix \\ Phoenix, Arizona
}

\begin{abstract}
The female genital tract is rarely involved by coccidioidomycosis. We describe a woman with disseminated coccidioidomycosis involving the female pelvic organs associated with elevated tumor markers CA 125 and CA 19-9. She had no fevers and the initial clinical suspicion was a malignancy because of the elevated tumor markers. At exploratory laparotomy a total abdominal hysterectomy and bilateral salpingooophorectomy were performed because of the suspicion of a malignancy. Subsequent pathology demonstrated coccidioidomycosis involving the female genital tract and no malignancy. The abnormal CA 125 and CA 19-9 returned to normal after surgical resection and treatment of the coccidioidomycosis.
\end{abstract}

\section{Introduction}

Dissemination of coccidioidomycosis to the female genital tract is an unusual complication of that fungal infection (1). This report describes a woman with disseminated coccidioidomycosis which mimicked a malignancy of the female genital tract. The initial clinical suspicion was a malignancy because of the elevation of carbohydrate antigen tumor markers CA125 and CA19-9.

\section{Case Report}

A 48-year-old Hispanic woman with a history of adult onset diabetes and menorrhagia presented with left lower quadrant pain. She denied fever, chills or sweats. She gave no history of "Valley Fever" or pneumonia. Physical examination was significant for left lower quadrant abdominal tenderness without rebound or guarding. CT of the abdomen and pelvis showed free fluid within the pelvis, masses within the uterus, left hydronephrosis and bilateral cystic masses of the adnexa. She was anemic and thrombocytopenic with a hemoglobin of $7.8 \mathrm{~g} / \mathrm{dL}$ and platelet count of $51,000 / \mathrm{mm}^{3}$. She received blood and platelet transfusions and was given oral prednisone $80 \mathrm{mg}$ once daily for five days which was associated with improvement of her platelet count to normal. Certain tumor markers were found to be elevated a CA 125 of 475.7 (normal range: 0-35 U/mL) and CA 19-9 of 133 (normal range: 0-37 U/mL). A carcinoembryonic 
antigen (CEA) was not elevated 1.9 (normal range 0-2.5 ng/ml). Her diabetes was controlled. The left hydronephrosis was treated with a ureteral stent and nephrostomy. An endometrial biopsy was consistent with benign endocervical and endometrial tissue. Percutaneous drainage of the left ovarian cyst fluid showed no malignant cells and no abscess. A plain chest x-ray was interpreted as normal, however a CT scan of the chest showed a left lower lobe lesion which was biopsied and found to be consistent with an old Coccidioides granuloma. Because of the concern for a pelvic malignancy, an exploratory laparotomy was done and a total hysterectomy with bilateral salpingooophorectomy was performed. The pathology of the surgical specimen showed Coccidioides with necrotizing granulomas and spherules in the round ligament, uterus, endometrium, bilateral ovaries and fallopian tubes (Figure 1).

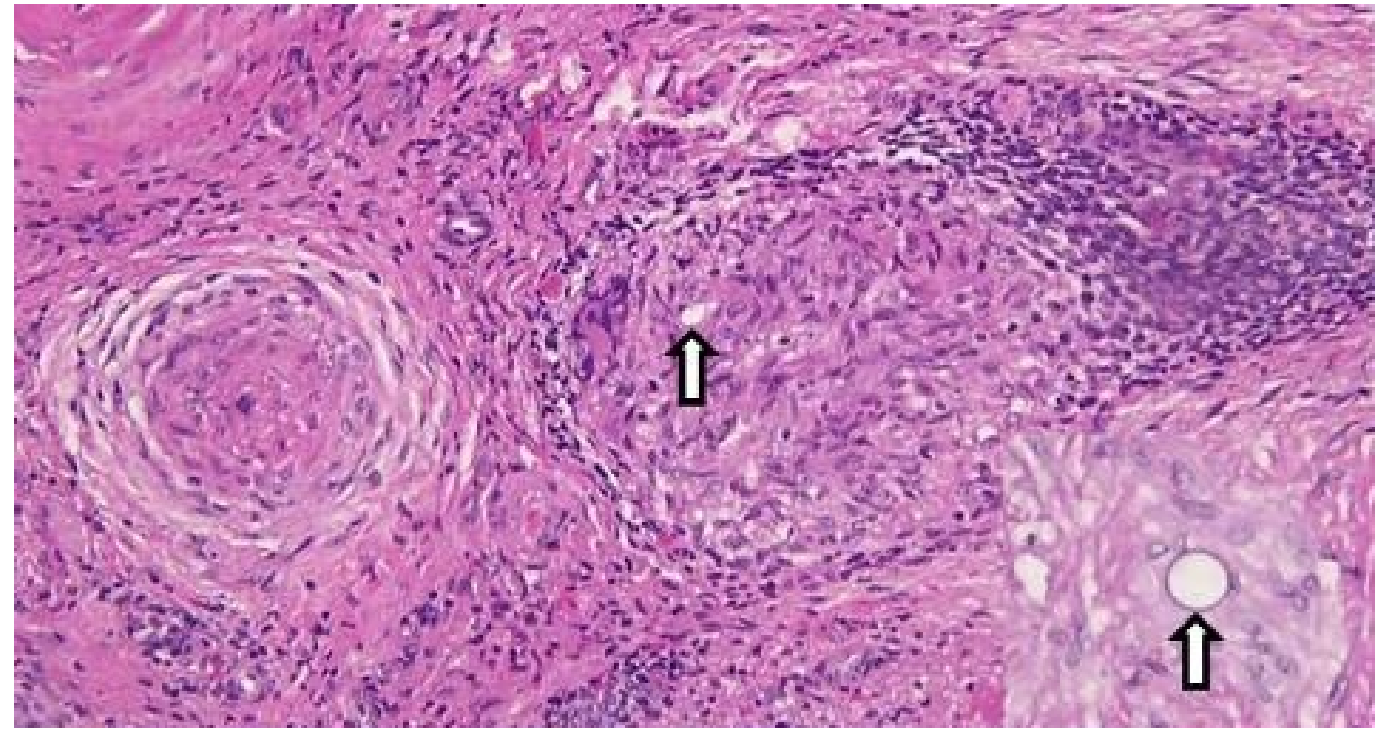

Figure 1. Hematoxylin and eosin stain of round ligament showing necrotizing granulomas associated with Coccidioides spherules (arrows). Empty Coccidioides spherule in inset.

Following the operation, she was started on oral fluconazole 400mg daily and followed as an outpatient. Her complement fixation titer for Coccidioides was positive at 1:64 on discharge, increased to 1:256 one month later and then declined to 1:8 five months later. At five months follow-up she was asymptomatic and back to her premorbid state. She was to remain on fluconazole indefinitely. Postoperatively the CA 125 and CA 19-9 returned to normal at 12.3 and 12.0 respectively after fifty days (Table 1 ).

Table 1. Tumor Marker Values Before and Fifty Days After Surgical Resection.

\begin{tabular}{|l|l|l|}
\hline Tumor Marker & Before & After \\
\hline $\begin{array}{l}\text { CA } 125 \\
\text { (0-35 U/mL) }\end{array}$ & 475.7 & 12.3 \\
\hline $\begin{array}{l}\text { CA } 19-9 \\
\text { (0-37 U/mL) }\end{array}$ & 133 & 12 \\
\hline
\end{tabular}




\section{Discussion}

Dissemination of Coccidioides to the female pelvic organs is unusual. In a series of 142 necropsies of patients who died of coccidioidomycosis, none of the thirty-three females had involvement of the genital tract (2). Presumptively the fungus spreads endogenously from the lung as in our patient. It is notable that the lung lesion in this patient was initially thought to be a malignancy. However, when "old Coccidioides granuloma" was reported, it was not associated with her genital tract problem by the treating physicians. We were able to find seventeen previously reported cases of coccidioidomycosis involving the female genital tract since the first report in 1929 (3-7). In those cases of Coccidioides involving the genital tract, there was no combination of investigations or clinical features that were sensitive enough to diagnose the female genital tract infection preoperatively. In fourteen of the eighteen patients (including our patient) with Coccidioides serologic test results, thirteen had a positive titer of 1:16 or greater (3-6).

In all eighteen cases the diagnosis of Coccidioides involving the genital tract was made only post-operatively after the microscopic examination of surgical specimens. Treatment of female genital tract coccidioidomycosis generally requires surgical resection of the involved tissues and antifungal agents (3). Cure of pelvic coccidioidomycosis by surgical resection alone, without antifungal therapy, has been reported in at least 5 cases $(3,7)$. However, deaths attributable to disseminated coccidioidomycosis with involvement of the genital tract despite treatment and surgery have been reported (8). Quantitative serologic testing can be useful in making the diagnosis and following the response to treatment. The complement fixation titers to Coccidioides would be expected to decrease with treatment and clinical improvement. Our patient's complement fixation titer went from a high of 1:256 to 1:8 after surgical resection and five months of treatment. In general, patients with disseminated coccidioidomycosis will respond to fluconazole, but the duration of therapy can be protracted for years.

Early in the course of our patient's workup, she was found to have elevated CA 125 and CA 19-9 levels, raising the suspicion of a malignancy. In general, tumor markers should not be used as a screening test for malignancy and are most useful for following the response to treatment. In this patient the response was to antifungal therapy rather than chemotherapy. We believe the tumor markers were elevated due to the inflammatory response to the Coccidioides infection $(4,9)$. CA 125 is most commonly monitored in the management of ovarian carcinoma. However, it is only $75-80 \%$ sensitive in patients with ovarian cancer and can also be elevated in a variety of benign conditions such as infection (10). In addition to the ovarian cancer cells, benign endometrial and peritoneal mesothelial cells can also secrete CA 125 (11). It appears that any process causing serosal inflammation may elevate CA 125. Thus non-tumorous conditions such as pelvic tuberculosis can result in sufficient inflammation to cause an increased CA 125 level (12). CA 19-9 is a serum marker associated with pancreatic cancer, but it also can be elevated in non-cancerous conditions such as pancreatitis, endometriosis and in diabetics with poor glycemic control $(10,13)$. 
Both CA 125 and CA 19-9 can be elevated in noncancerous conditions such as infection and presumed to be the reason for the elevation in our patient. Her surgical histopathology showed concomitant endometriosis of the round ligament, uterine serosa and both ovaries (Figure 2).

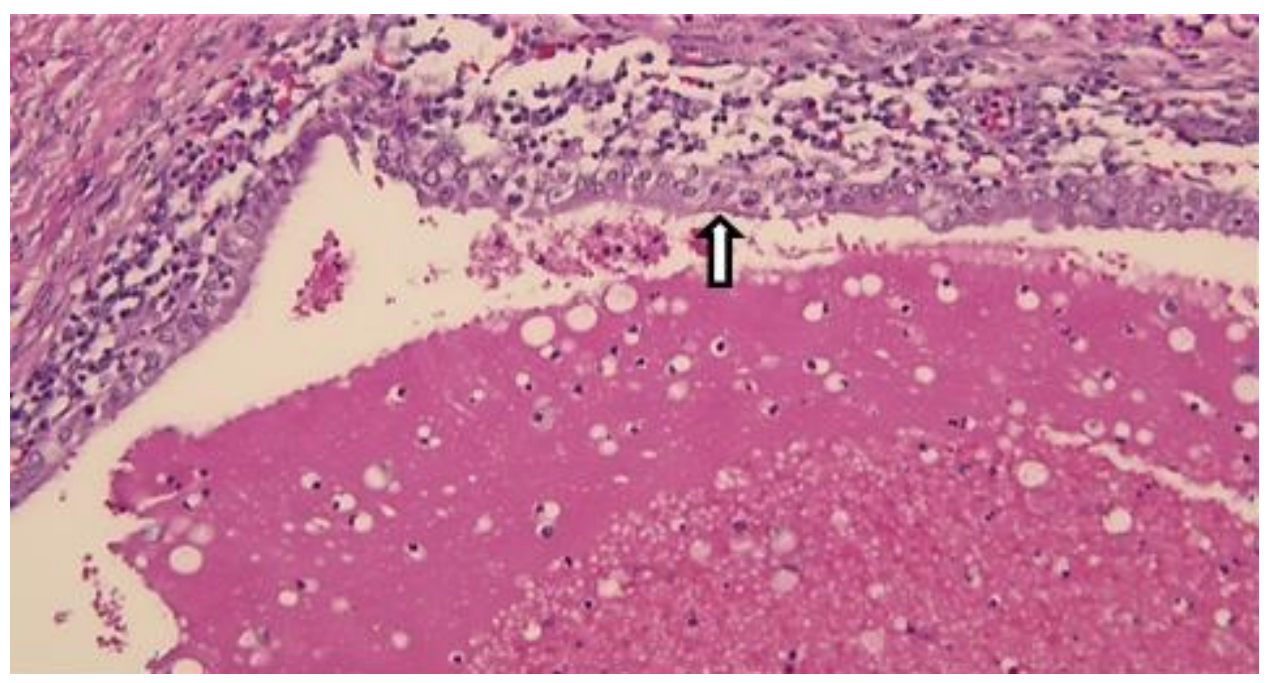

Figure 2. Hematoxylin and eosin stain of ovary showing changes consistent with endometriosis (arrow).

This was in addition to the necrotizing granulomas containing Coccidioides spherules (Figure 1). Increased levels of CA 125 have been reported previously in three patients with Coccidioides involving pelvic organs $(4,5,7)$, but there have been no reports of elevated serum CA 19-9 levels. Endometriosis alone can cause both CA 125 and CA $19-9$ to be increased $(14,15)$, however the mechanism by which these markers become elevated is not completely understood. It has been postulated that chronic inflammation causes an epithelial reaction that results in the leakage of the tumor markers into the circulation $(14,15)$. Endometriosis due to a variety of infectious etiologies can cause serum CA 125 levels to be elevated and they can precipitously decrease following surgical intervention, as in our patient $(4,5)$. CA 19-9 levels have also been found to return to normal following surgical intervention for endometriosis (16). We presume that the elevated tumor markers in our patient were the result of similar inflammatory mechanisms observed for both CA 125 and CA 19-9. We suspect the reason that CA 19-9 levels have not been reported previously is that this test would be ordered less frequently in patients suspected of having a pelvic malignancy. Our patient had a normal CEA level consistent with a lack of involvement of the gastrointestinal tract by coccidioidomycosis.

Another potential source of Coccidioides infecting the female genital tract is sexual transmission. We could find no references to document sexual transmission of Coccidioides. However, transmission from a man with prostate involvement to a woman who developed an infection of her genital tract could occur, but our patient's husband had no prostate disease, no history of Valley Fever and his Coccidioides serology was 
negative. Coccidioides has been documented to mimic a variety of malignancies such as breast cancer, bronchogenic carcinoma, osteosarcoma and lymphoma (6). It is notable that the first reported case of coccidioidomycosis in 1892 was initially misdiagnosed as mycosis fungoides (6). Coccidioidomycosis is known to have protean manifestations and in this patient it mimicked a female genital tract malignancy. This case is unique because a Coccidioides infection was documented and associated with the elevation of tumor markers CA 19-9 and CA 125, which returned to normal following treatment and surgical resection of the involved tissues. Involvement of the female genital tract by coccidioidomycosis may be uncommon, but in endemic areas it should be a consideration in the differential diagnosis in women with a suspected pelvic malignancy and elevated levels of CA 125 and CA 19-9.

\section{References}

1. Saw EC, Smale LE, Einstein H, Huntington RW,Jr. Female genital coccidioidomycosis. Obstet Gynecol. 1975;45:199-202. [PubMed]

2. Huntington RW Jr., Waldmann WJ, Sargent JA, O'Connell H, Wybel R, Croll D. pathological and clinical observations in 142 cases of fatal coccidioidomycosis on necropsy. In Ajello L, ed. Proceedings of the Second Coccidioidomycosis Symposium. Tuscon, The University of Arizona Press.1967:143-167.

3. Chowfin A, Tight R. Female genital coccidioidomycosis (FGC), Addison's disease and sigmoid loop abscess due to Coccidioides immites; case report and review of literature on FGC. Mycopathologia. 1999;145:121-126. [CrossRef] [PubMed]

4. Ellis MW, Dooley DP, Sundborg MJ, Joiner LL, Kost ER. Coccidioidomycosis mimicking ovarian cancer. Obstet Gynecol. 2004;104:1177-1179. [CrossRef] [PubMed]

5. Micha JP, Goldstein BH, Robinson PA, Rettenmaier MA, Brown JV. Abdominal/pelvic Coccidioidomycosis. Gynecol Oncol. 2005;96:256-258. [CrossRef] [PubMed]

6. Crum-Cianflone NF, Truett AA, Teneza-Mora N, et al. Unusual presentations of coccidioidomycosis: a case series and review of the literature. Medicine (Baltimore). 2006;85:263-277. [CrossRef] [PubMed]

7. Smith G, Hoover S, Sobonya R, Klotz SA. Abdominal and pelvic coccidioidomycosis. Am J Med Sci. 2011;341:308-311. [CrossRef] [PubMed]

8. Bylund DJ, Nanfro JJ, Marsh WL,Jr. Coccidioidomycosis of the female genital tract. Arch Pathol Lab Med. 1986;110:232-235. [PubMed]

9. Bast RC,Jr, Xu FJ, Yu YH, Barnhill S, Zhang Z, Mills GB. CA 125: the past and the future. Int J Biol Markers. 1998;13:179-187. [PubMed]

10. Cancer antigen 125. In: Ferri FF, ed. Ferri's Clinical Advisor 2013 : 5 Books in 1. 1st ed. St. Louis, Mo: Elsevier Mosby; 2013:1452-1453.

11. Sevinc A, Camci C, Turk HM, Buyukberber S. How to interpret serum CA 125 levels in patients with serosal involvement? A clinical dilemma. Oncology. 2003;65:1-6. [CrossRef] [PubMed]

12. Sheth SS. Elevated CA 125 in advanced abdominal or pelvic tuberculosis. Int J Gynaecol Obstet. 1996;52:167-171. [CrossRef] [PubMed] 
13. Yu H, Li R, Zhang L, Chen H, Bao Y, Jia W. Serum CA19-9 level associated with metabolic control and pancreatic beta cell function in diabetic patients. Exp Diabetes Res. 2012;2012:745189. [CrossRef] [PubMed]

14. Kurata H, Sasaki M, Kase H, Yamamoto Y, Aoki Y, Tanaka K. Elevated serum CA125 and CA19-9 due to the spontaneous rupture of ovarian endometrioma. Eur J Obstet Gynecol Reprod Biol. 2002;105:75-76. [CrossRef] [PubMed]

15. Park BJ, Kim TE, Kim YW. Massive peritoneal fluid and markedly elevated serum CA125 and CA19-9 levels associated with an ovarian endometrioma. J Obstet Gynaecol Res. 2009;35:935-939. [CrossRef] [PubMed]

16. Takemori M, Sugimura K. Ovarian chocolate cyst with markedly elevated serum CA19-9 level: a case report. Eur J Obstet Gynecol Reprod Biol. 1991;42:241-244. [CrossRef] [PubMed] 